Supporting Information for:

\title{
Biorenewable Epoxy Resins Derived from Plant-Based Phenolic Acids
}

Guozhen Yang, Brian J. Rohde, Hiruy Tesefay, and Megan L. Robertson*

Department of Chemical and Biomolecular Engineering, University of Houston, Houston, TX, 77204-4004, United States

*Corresponding author 4726 Calhoun Road S222 Engineering Building 1

University of Houston Houston, TX 77204-4004

mlrobertson@uh.edu

713-743-2748

\section{Includes:}

\section{9 pages}

16 figures

2 tables

1 scheme 


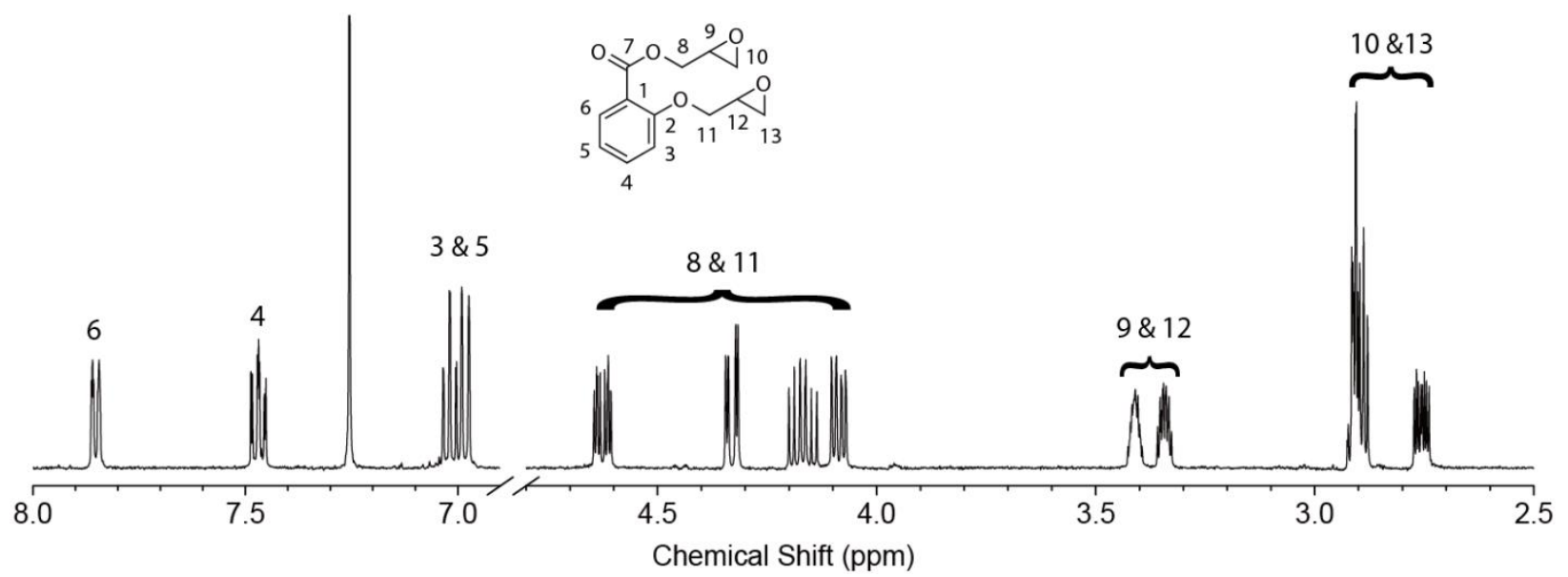

Figure S1a: A closer view of ${ }^{1} \mathrm{H}$ NMR data obtained from ESA.

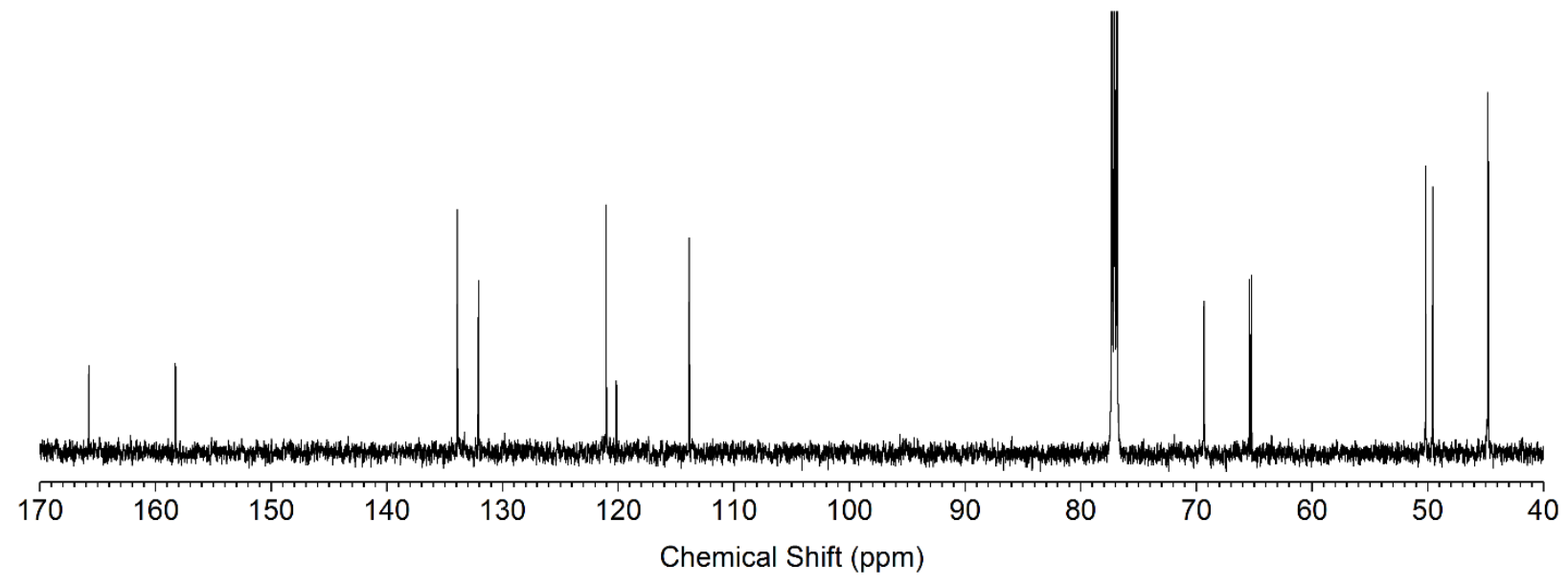

Figure S1b: ${ }^{13} \mathrm{C}$ NMR data obtained from ESA. 


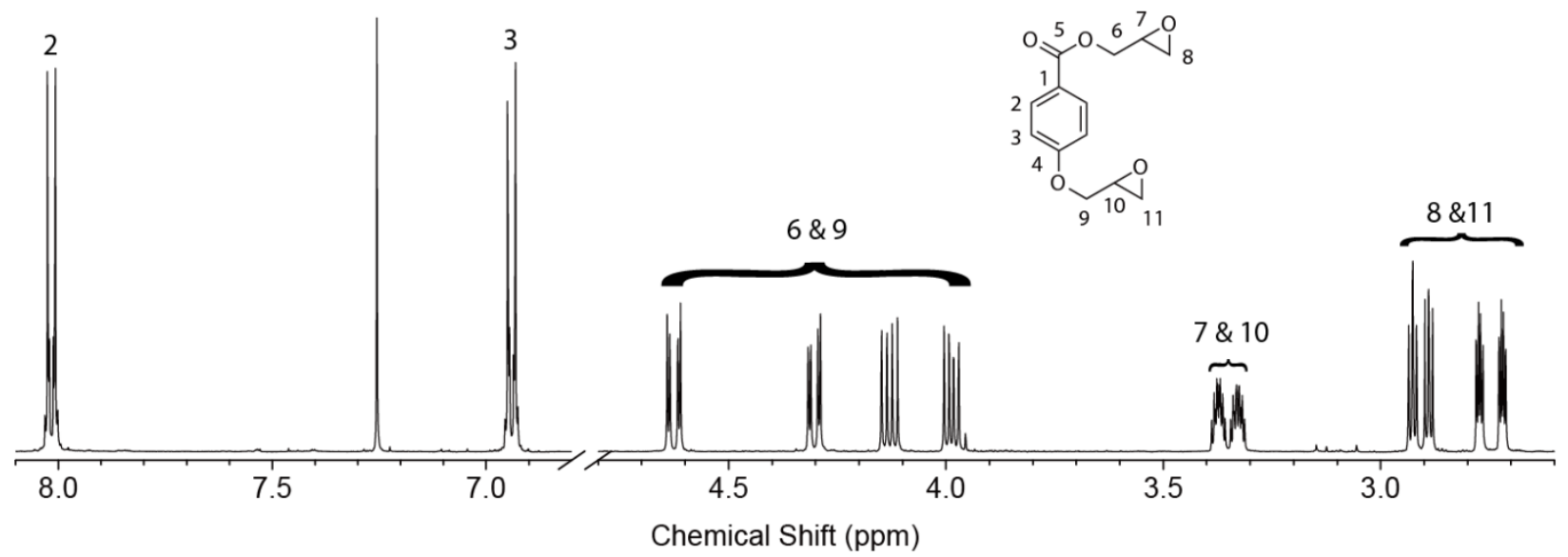

Figure S2a: A closer view of ${ }^{1} \mathrm{H}$ NMR data obtained from E4HBA.

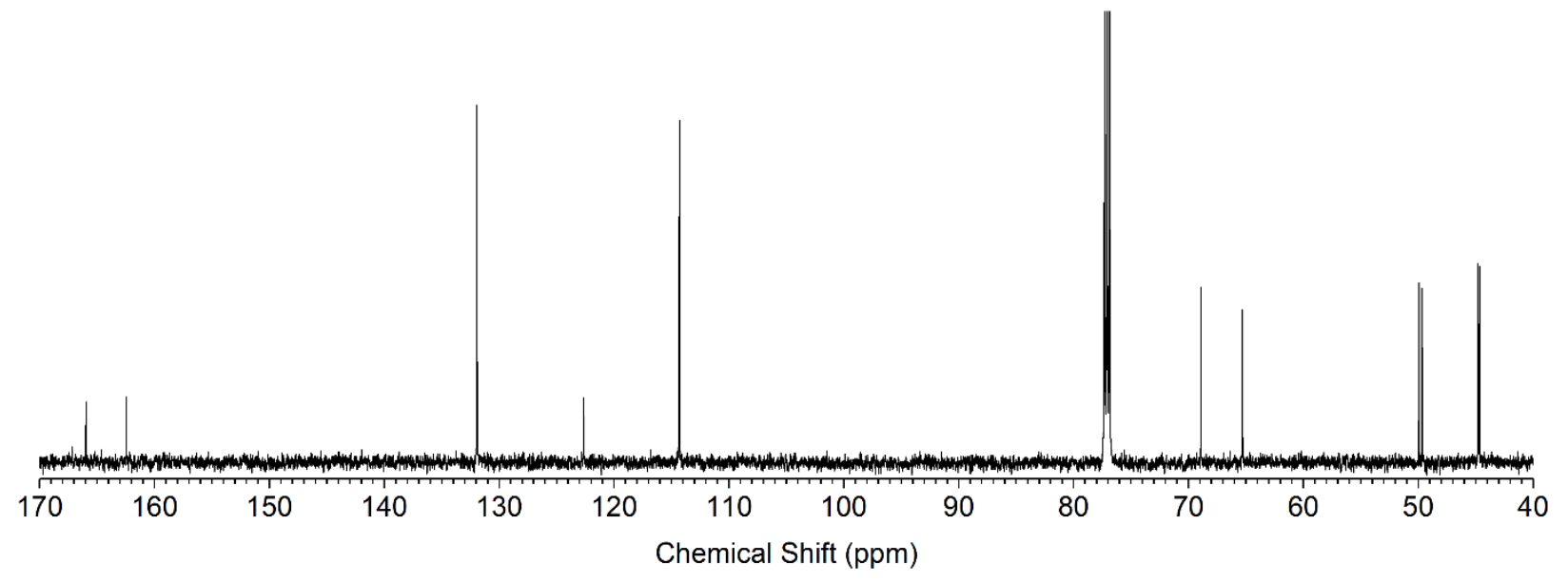

Figure S2b: ${ }^{13} \mathrm{C}$ NMR data obtained from E4HBA. 


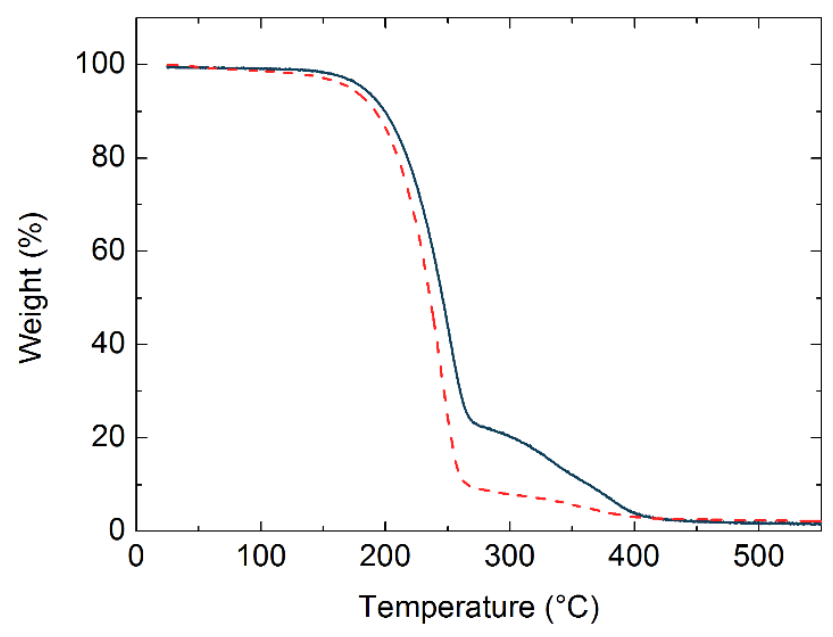

Figure S3: Weight $\%$ as a function of temperature (obtained from TGA) for ESA (dark blue solid curve) and E4HBA (red dashed curve). The temperature was heated from 25 to $550{ }^{\circ} \mathrm{C}$ at a rate of $10{ }^{\circ} \mathrm{C} / \mathrm{min}$. 

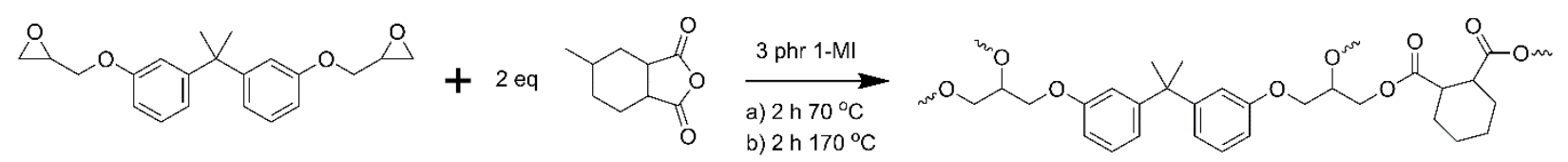

Scheme S1: Synthesis of epoxy resins through curing of DGEBA (catalyzed by 3 phr 1-MI)

Table S1: Amounts of Epoxy Monomer and Curing Agent Used in Epoxy Resin Synthesis

\begin{tabular}{c|c|cccc|cccc}
\hline & \multirow{2}{*}{$\begin{array}{c}\text { Epoxy } \\
\text { Epoxy }\end{array}$} & \multicolumn{4}{|c|}{ Amine Mass (g) } & \multicolumn{4}{c}{ Anhydride Mass (g) } \\
\cline { 3 - 10 } Monomer & TETA & DETA & MXDA & IPDA & MHHPA & 1-MI & NMA & K54 \\
\hline ESA & 1 & 0.195 & 0.165 & 0.272 & 0.340 & 1.34 & 0.03 & 1.42 & 0.03 \\
E4HBA & 1 & 0.195 & 0.165 & 0.272 & 0.340 & 1.34 & 0.03 & 1.42 & 0.03 \\
DGEBA & 1 & 0.141 & 0.119 & 0.197 & 0.246 & 0.97 & 0.03 & 1.03 & 0.03 \\
\hline
\end{tabular}




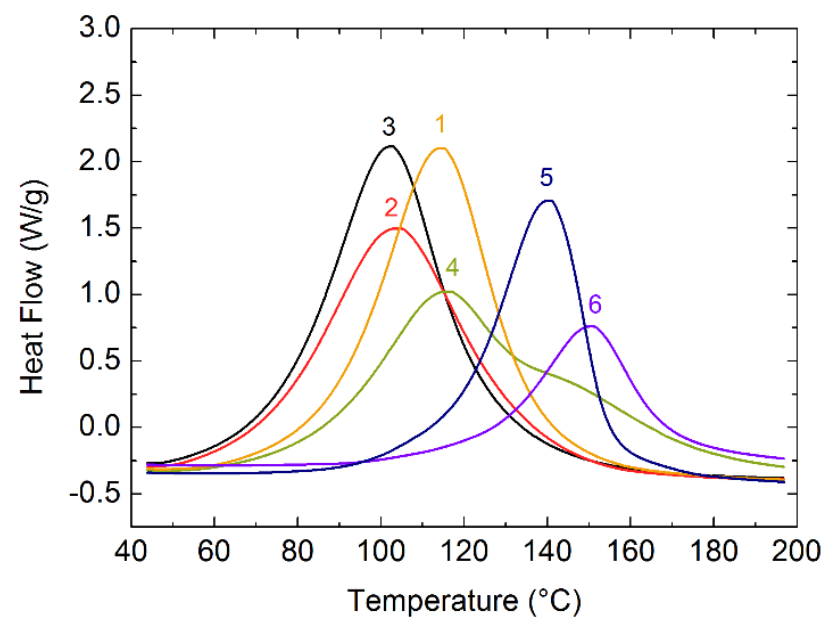

Figure S4: Heat flow as a function of temperature (obtained from DSC) for DGEBA cured with different curing agents: MXDA (yellow curve, 1), TETA (red curve, 2), DETA (black curve, 3), IPDA (green curve, 4), MHHPA (+ 3 phr 1-MI, dark blue curve, 5), NMA (+ 3 phr K54, purplecurve, 6 ). The experiments were terminated at $200{ }^{\circ} \mathrm{C}$ to avoid thermal degradation of the sample in the calorimeter. 
ESA-Based Epoxy Resin
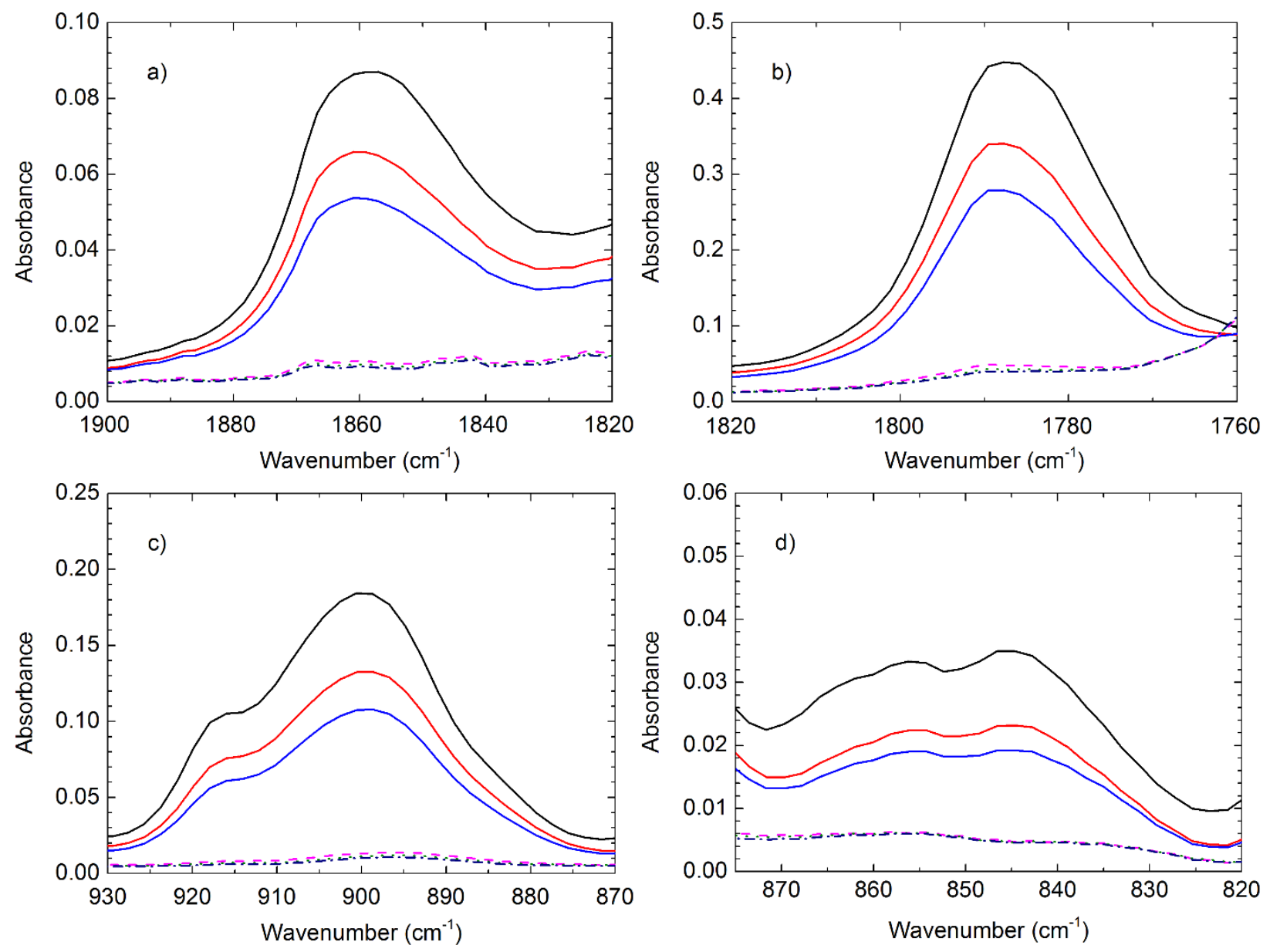

Figure S5 : A closer view of FTIR data (transmission mode) obtained from a mixture of anhydride, 1-MI (3 phr), and ESA at a) $1857 \mathrm{~cm}^{-1}$, b) $1787 \mathrm{~cm}^{-1}$, c) $915 \mathrm{~cm}^{-1}$, d) $845 \mathrm{~cm}^{-1}$. Data were obtained before curing (black solid curve) and after the following curing times and temperatures: $1 \mathrm{~h}$ at 70 ${ }^{\circ} \mathrm{C}$ (red solid curve), $2 \mathrm{~h}$ at $70{ }^{\circ} \mathrm{C}$ (blue solid curve), $2 \mathrm{~h}$ at $70{ }^{\circ} \mathrm{C}$ followed by $1 \mathrm{~h}$ at $170{ }^{\circ} \mathrm{C}$ (pink dashed curve), $2 \mathrm{~h}$ at $70{ }^{\circ} \mathrm{C}$ followed by $2 \mathrm{~h}$ at $170{ }^{\circ} \mathrm{C}$ (green dotted curve), and $2 \mathrm{~h}$ at $70{ }^{\circ} \mathrm{C}$ followed by $3 \mathrm{~h}$ at $170{ }^{\circ} \mathrm{C}$ (dark blue dashed curve). The epoxy monomer and curing agent were used at the stoichiometric ratios (Table S1). The pink dashed, green dotted, and dark blue dashed curves are overlapping. 
E4HBA-Based Epoxy Resin
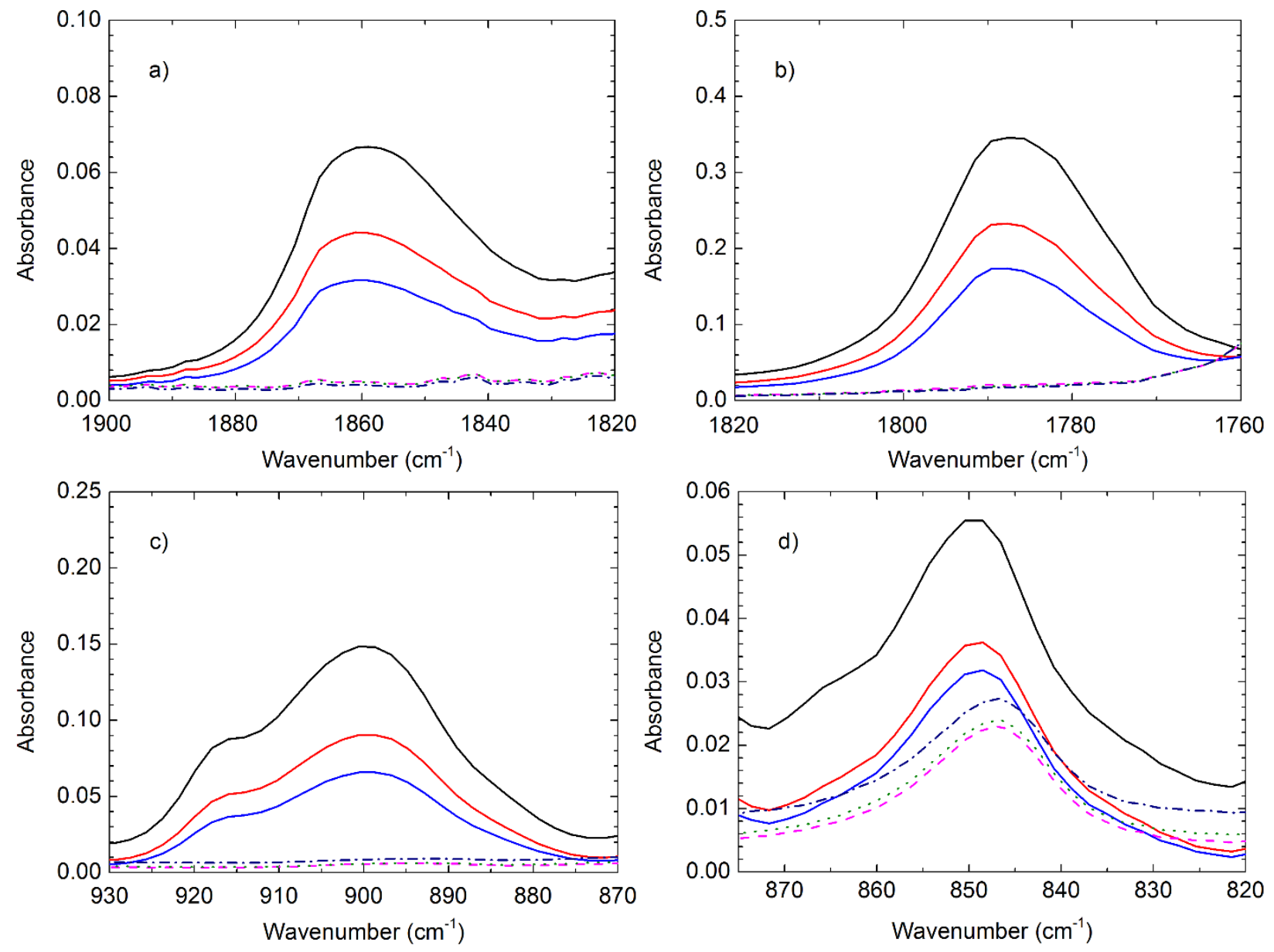

Figure S6 : A closer view of FTIR data (transmission mode) obtained from a mixture of anhydride, 1-MI (3 phr), and E4HBA at a) $1857 \mathrm{~cm}^{-1}$, b) $1787 \mathrm{~cm}^{-1}$, c) $915 \mathrm{~cm}^{-1}$, d) $845 \mathrm{~cm}^{-1}$. Data were obtained before curing (black solid curve) and after the following curing times and temperatures: $1 \mathrm{~h}$ at $70{ }^{\circ} \mathrm{C}$ (red solid curve), $2 \mathrm{~h}$ at $70{ }^{\circ} \mathrm{C}$ (blue solid curve), $2 \mathrm{~h}$ at $70{ }^{\circ} \mathrm{C}$ followed by $1 \mathrm{~h}$ at 170 ${ }^{\circ} \mathrm{C}$ (pink dashed curve), $2 \mathrm{~h}$ at $70{ }^{\circ} \mathrm{C}$ followed by $2 \mathrm{~h}$ at $170{ }^{\circ} \mathrm{C}$ (green dotted curve), and $2 \mathrm{~h}$ at 70 ${ }^{\circ} \mathrm{C}$ followed by $3 \mathrm{~h}$ at $170{ }^{\circ} \mathrm{C}$ (dark blue dashed curve). The epoxy monomer and curing agent were used at the stoichiometric ratios (Table S1). The pink dashed, green dotted, and dark blue dashed curves are overlapping. The peak remaining after curing at $847 \mathrm{~cm}^{-1}$ is attributed to the in-phase, out-of-plane $\mathrm{C}-\mathrm{H}$ wagging vibration of two adjacent hydrogens on the aromatic ring. ${ }^{1}$ 
DGEBA-Based Epoxy Resin
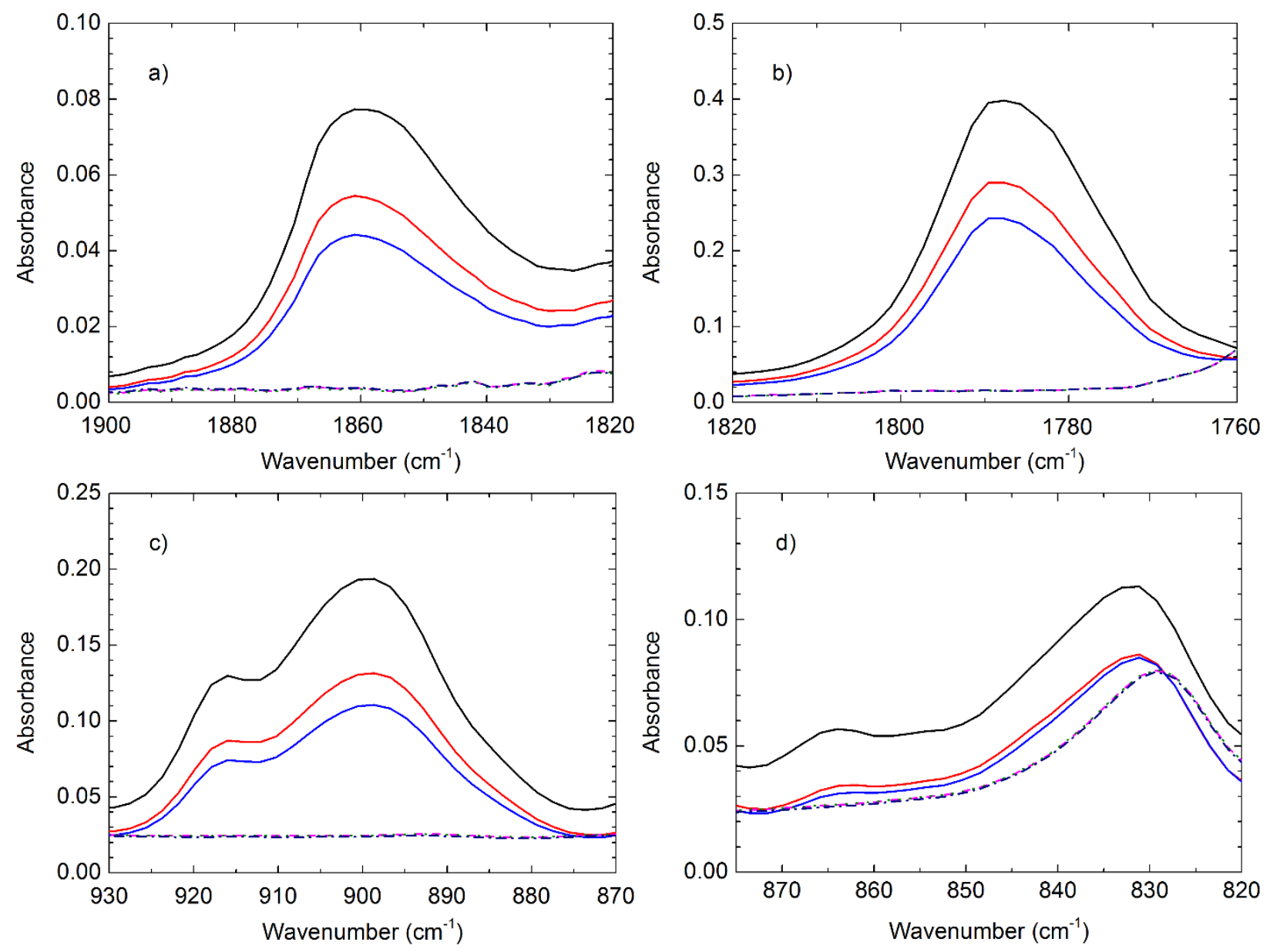

Figure S7 : A closer view of FTIR data (transmission mode) obtained from a mixture of anhydride, 1-MI (3 phr), and DGEBA at a) $1857 \mathrm{~cm}^{-1}$, b) $1787 \mathrm{~cm}^{-1}$, c) $915 \mathrm{~cm}^{-1}$, d) $845 \mathrm{~cm}^{-1}$. Data were obtained before curing (black solid curve) and after the following curing times and temperatures: $1 \mathrm{~h}$ at $70{ }^{\circ} \mathrm{C}$ (red solid curve), $2 \mathrm{~h}$ at $70^{\circ} \mathrm{C}$ (blue solid curve), $2 \mathrm{~h}$ at $70{ }^{\circ} \mathrm{C}$ followed by $1 \mathrm{~h}$ at 170 ${ }^{\circ} \mathrm{C}$ (pink dashed curve), $2 \mathrm{~h}$ at $70{ }^{\circ} \mathrm{C}$ followed by $2 \mathrm{~h}$ at $170{ }^{\circ} \mathrm{C}$ (green dotted curve), and $2 \mathrm{~h}$ at 70 ${ }^{\circ} \mathrm{C}$ followed by $3 \mathrm{~h}$ at $170{ }^{\circ} \mathrm{C}$ (dark blue dashed curve). The epoxy monomer and curing agent were used at the stoichiometric ratios (Table S1). The pink dashed, green dotted, and dark blue dashed curves are overlapping. The peak remaining after curing at $829 \mathrm{~cm}^{-1}$ is attributed to the in-phase, out-of-plane $\mathrm{C}-\mathrm{H}$ wagging vibration of two adjacent hydrogens on the aromatic ring. ${ }^{1}$ 
Table S2: Conversion of Epoxy Resins Quantified through FTIR ${ }^{\mathrm{a}}$

\begin{tabular}{|c|c|c|c|c|c|c|}
\hline \multirow{2}{*}{$\begin{array}{c}\text { Curing } \\
\text { Time }(\mathrm{h})^{\mathrm{b}} \\
\text { at } 70{ }^{\circ} \mathrm{C} / \\
170{ }^{\circ} \mathrm{C} \\
\end{array}$} & \multicolumn{2}{|c|}{ ESA } & \multicolumn{2}{|c|}{ E4HBA } & \multicolumn{2}{|c|}{ DGEBA } \\
\hline & $1857 \mathrm{~cm}^{-1}$ & $1787 \mathrm{~cm}^{-1}$ & $1857 \mathrm{~cm}^{-1}$ & $1787 \mathrm{~cm}^{-1}$ & $1857 \mathrm{~cm}^{-1}$ & $1787 \mathrm{~cm}^{-1}$ \\
\hline $1 / 0$ & $28 \pm 3 \%$ & $26 \pm 2 \%$ & $36 \pm 3 \%$ & $34 \pm 2 \%$ & $29 \pm 2 \%$ & $29 \pm 1 \%$ \\
\hline $2 / 0$ & $44 \pm 3 \%$ & $40 \pm 2 \%$ & $55 \pm 3 \%$ & $53 \pm 2 \%$ & $43 \pm 2 \%$ & $40 \pm 1 \%$ \\
\hline $2 / 1$ & $94 \pm 3 \%$ & $90 \pm 2 \%$ & $97 \pm 3 \%$ & $96 \pm 2 \%$ & $99.5 \pm 0.8 \%$ & $97 \pm 1 \%$ \\
\hline $2 / 2$ & $96 \pm 3 \%$ & $93 \pm 2 \%$ & $97 \pm 3 \%$ & $97 \pm 2 \%$ & $100^{c}$ & $97 \pm 1 \%$ \\
\hline $2 / 3$ & $96 \pm 3 \%$ & $94 \pm 2 \%$ & $97 \pm 3 \%$ & $97 \pm 2 \%$ & $100^{c}$ & $97 \pm 1 \%$ \\
\hline
\end{tabular}

${ }^{a}$ Error bars represent error on analysis of conversion from FTIR peak areas.

${ }^{\mathrm{b}}$ Samples were cured in the convection oven. Samples were first cured for the specified time at $70{ }^{\circ} \mathrm{C}$, followed by curing at the specified time at $170{ }^{\circ} \mathrm{C}$.

${ }^{\mathrm{c}}$ Peak could not be detected. 


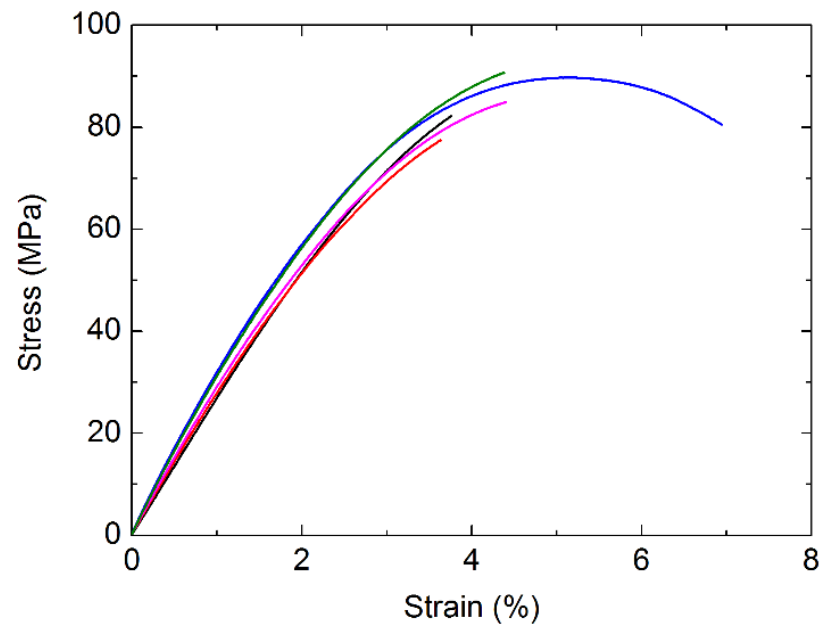

Figure S8: Stress-strain curves obtained from five independent specimens of ESA-based epoxy resins.

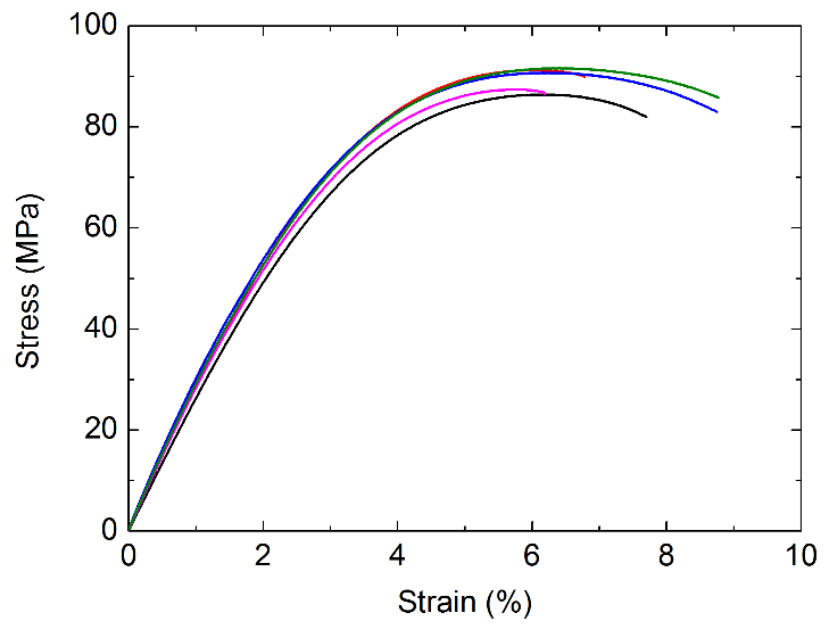

Figure S9: Stress-strain curves obtained from five independent specimens of E4HBA-based epoxy resins. 

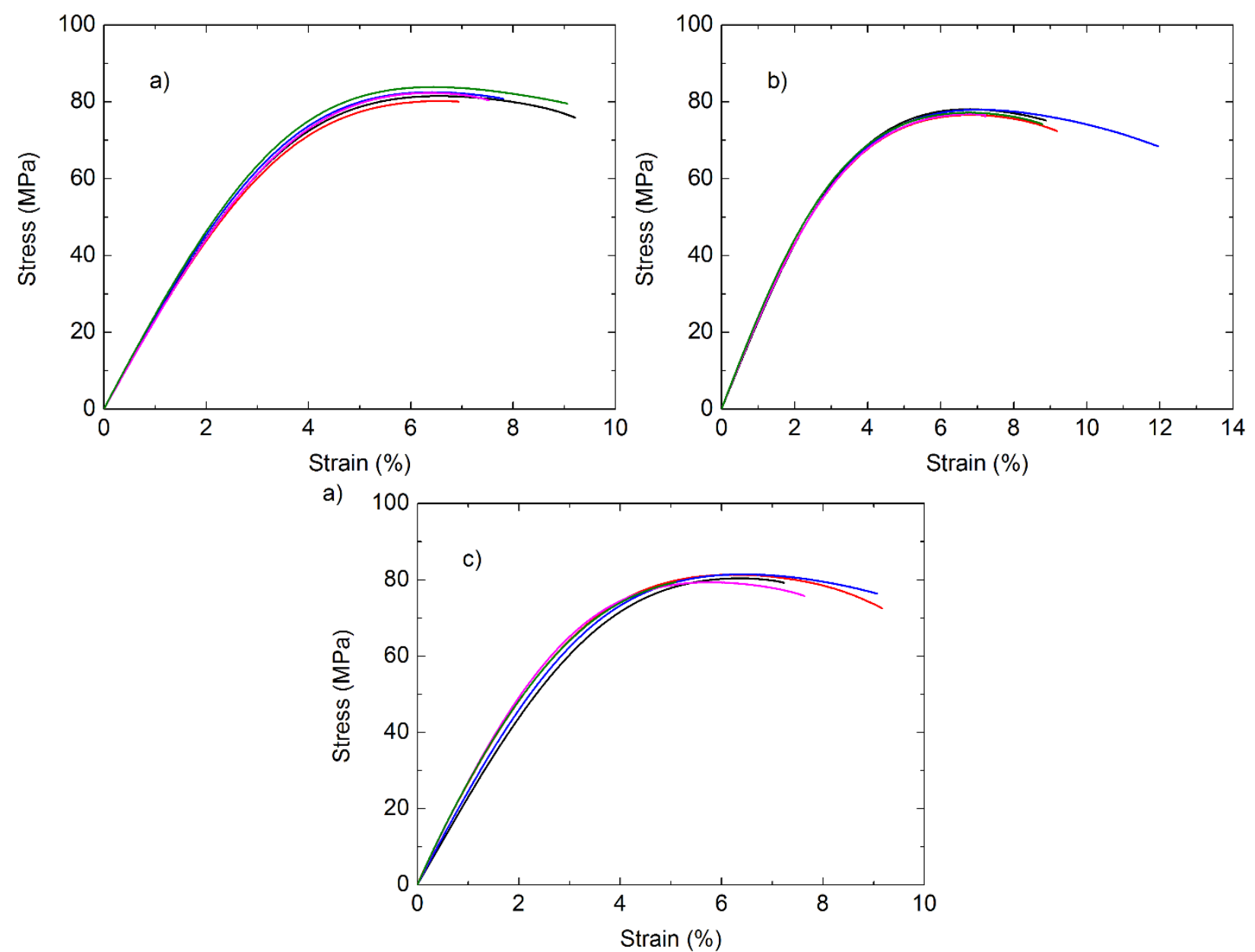

Figure S10: Stress-strain curves obtained from three batches with five independent specimens for each of DGEBA-based epoxy resins. 


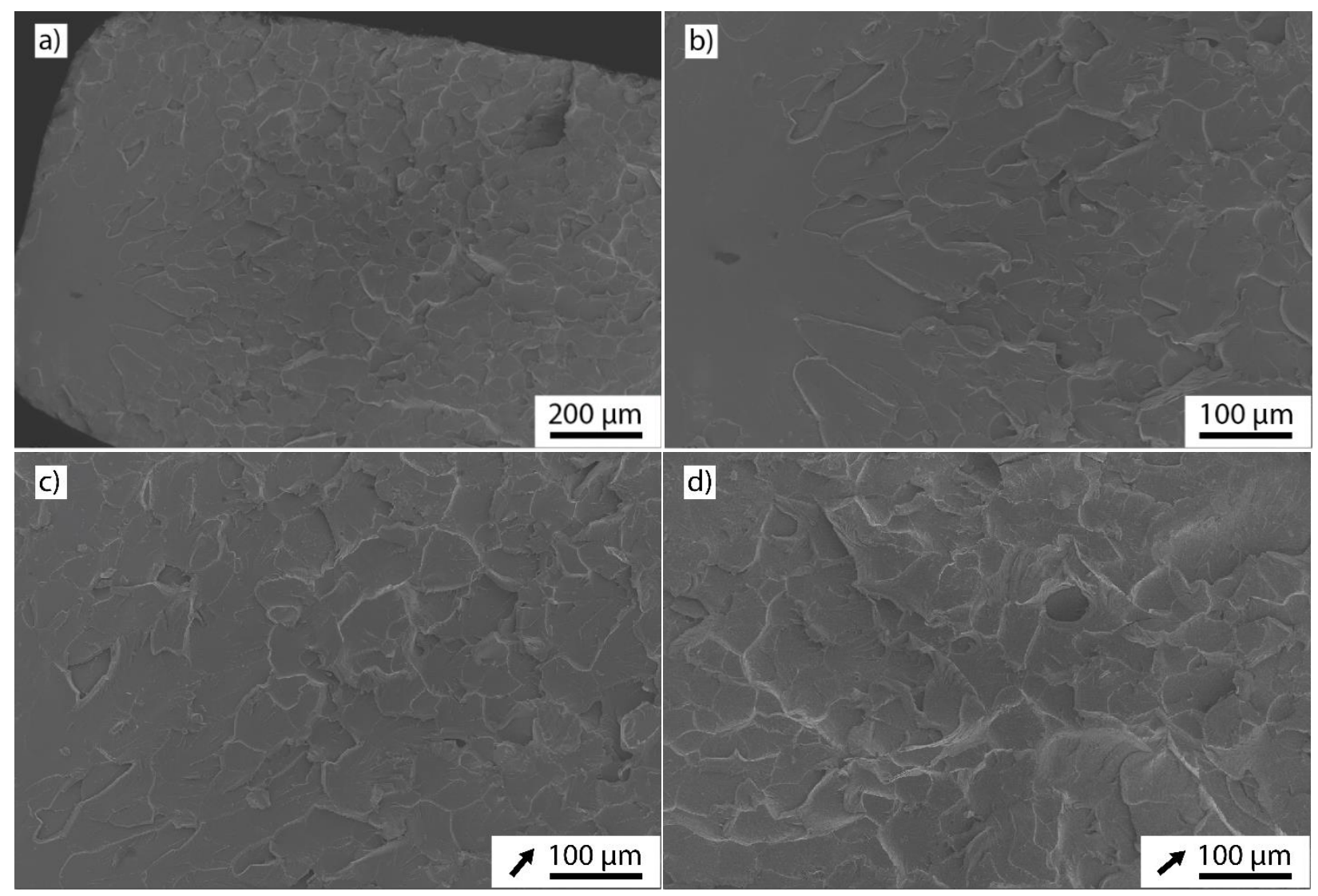

Figure S11: SEM micrographs of the fracture surface of ESA epoxy resins after tensile test: a) the fracture surace $(\times 200), b)$ the crack initiation site $(\times 400), c)$ and $d)$ crack propragation $(\times 400)$. 


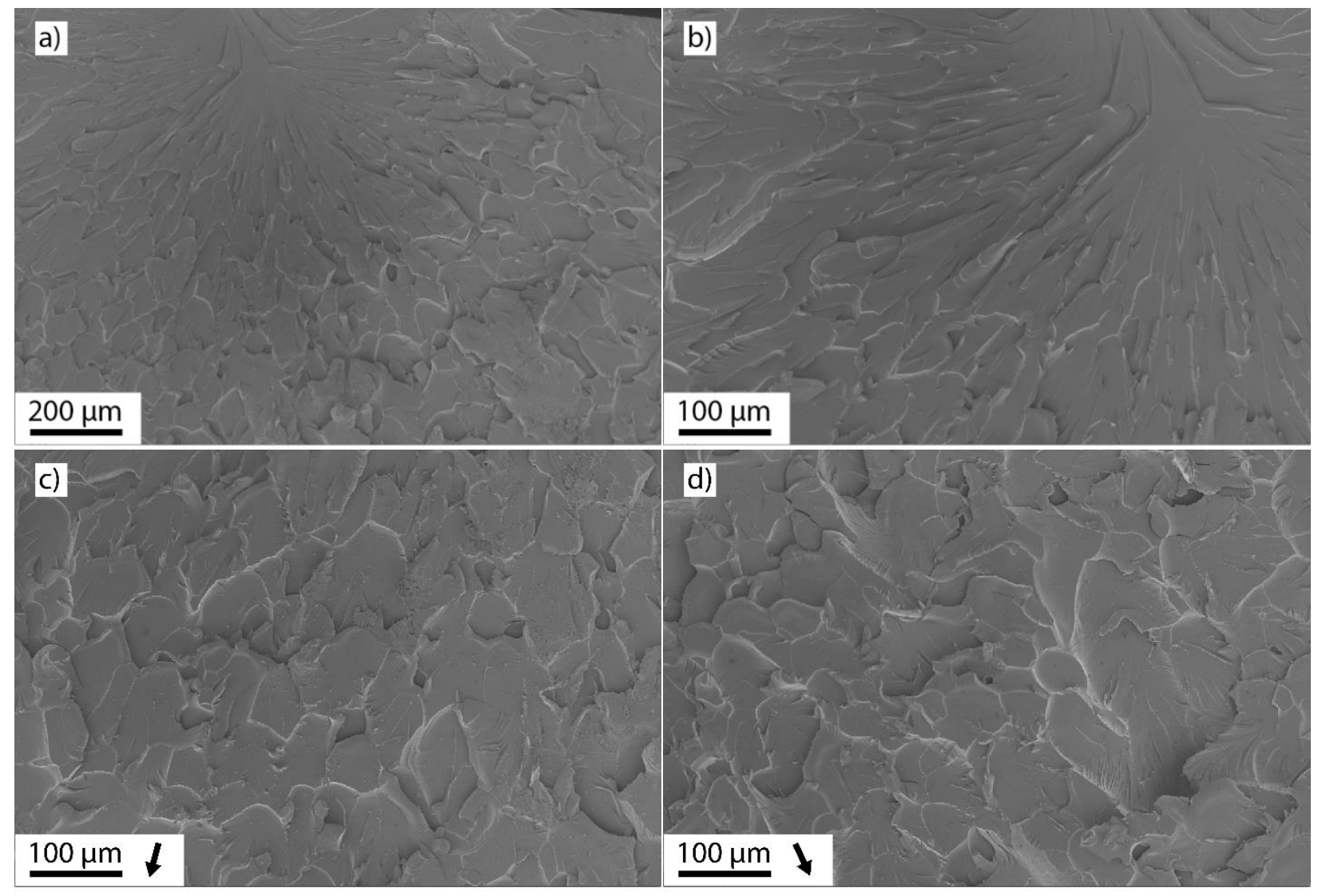

Figure S12: SEM micrographs of the fracture surface of E4HBA epoxy resins after tensile test: a) the fracture surace $(\times 200), b)$ the crack initiation site $(\times 400), c)$ and d) crack propregation $(\times 400)$. 

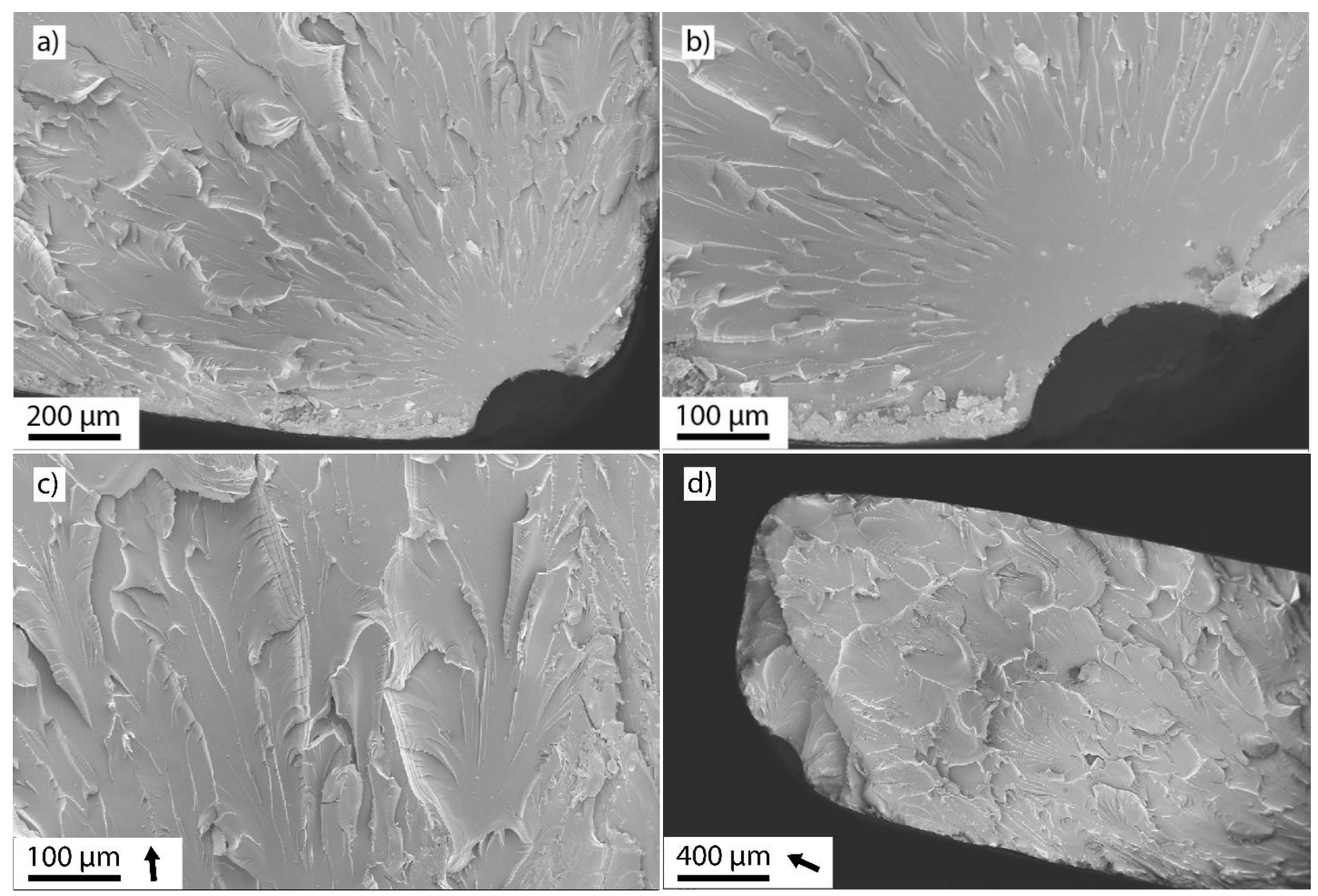

Figure S13: SEM micrographs of the fracture surface of DGEBA epoxy resins after tensile test: a) the fracture surace $(\times 200), b)$ the crack initiation site $(\times 400), c)$ and d) crack propregation $(\times 400)$. 


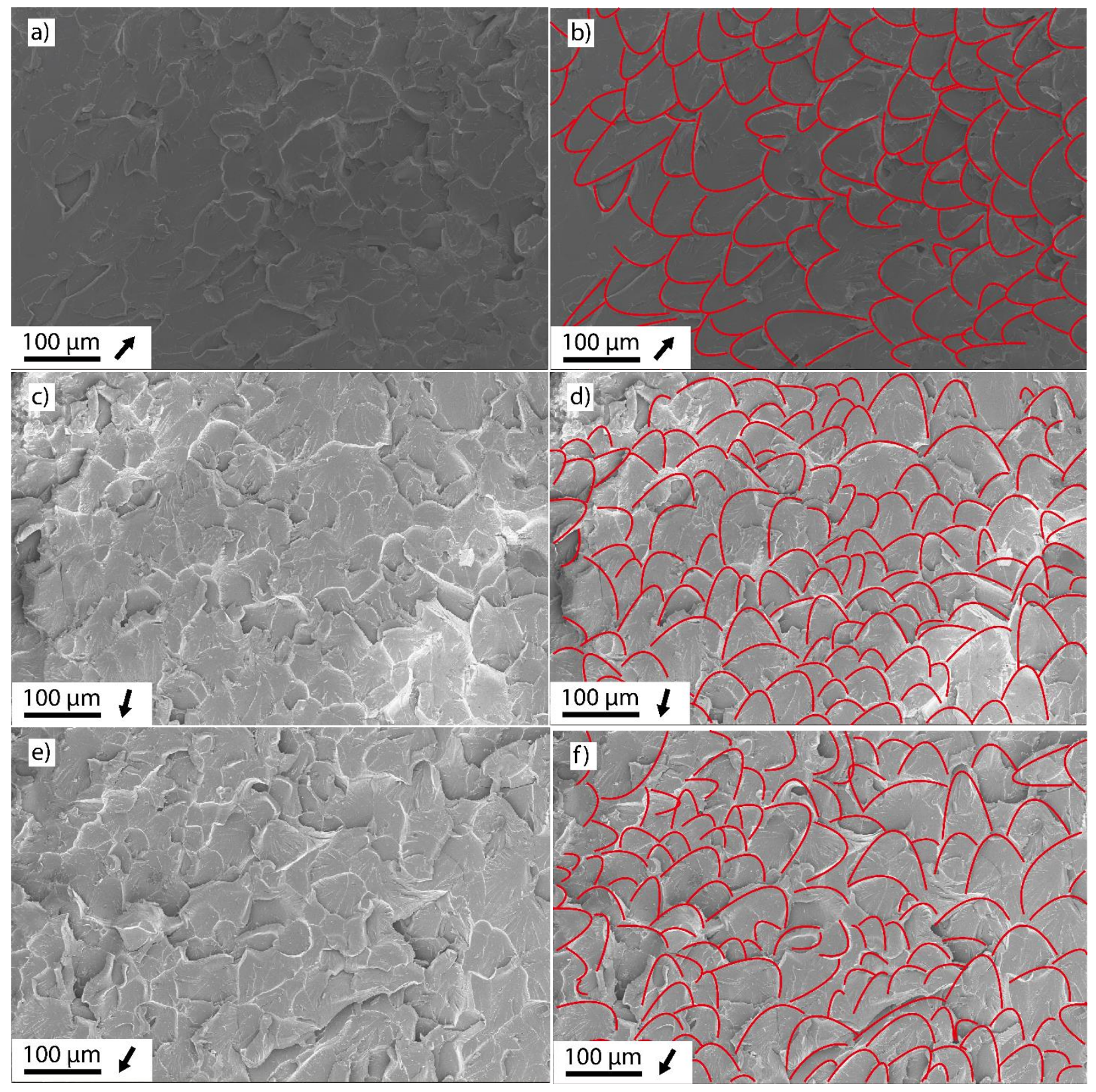

Figure S14: SEM micrographs of the fracture surface (grey level) of ESA epoxy resins after tensile test with the feature identification (red lines). 


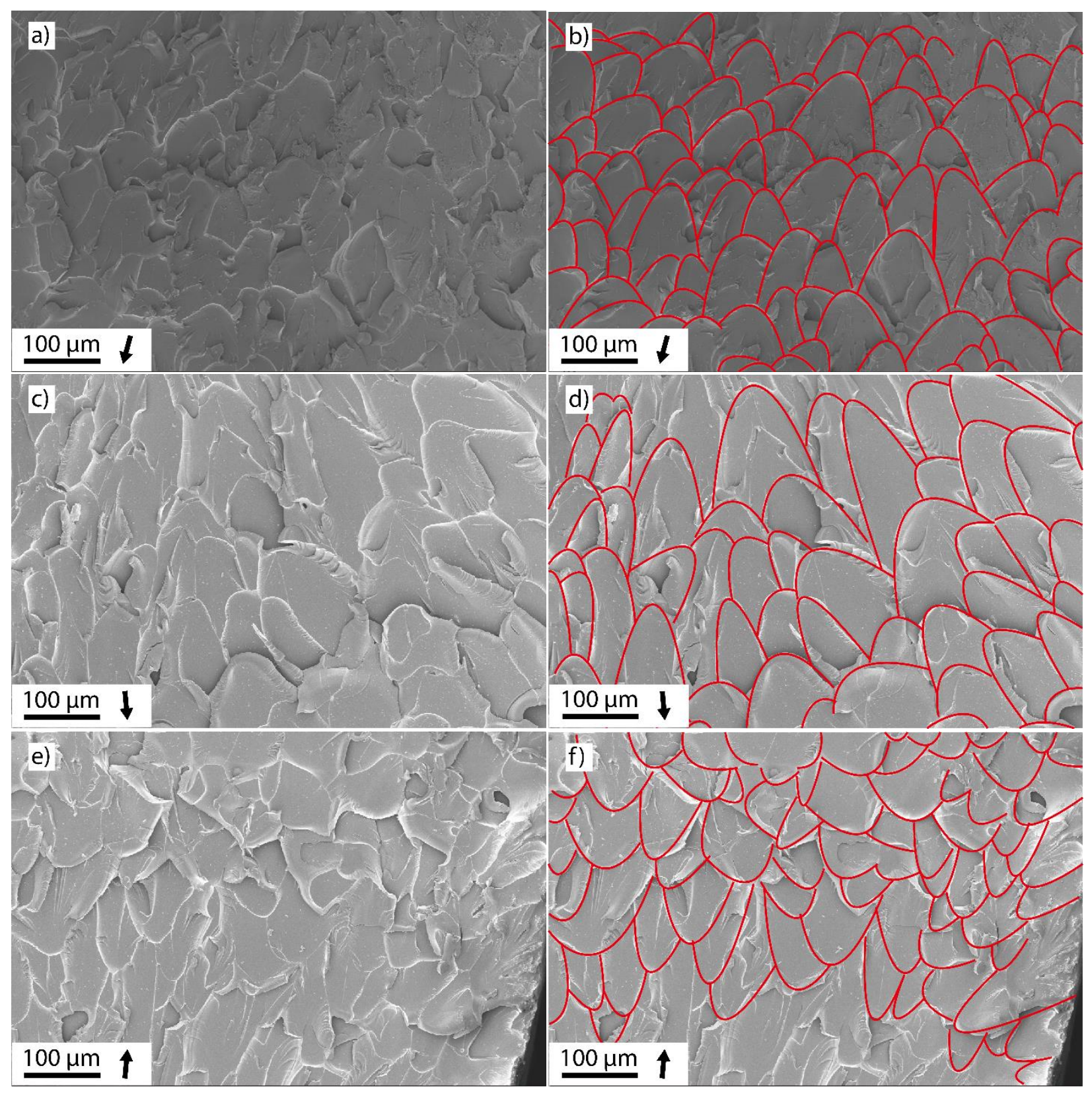

Figure S15: SEM micrographs of the fracture surface (grey level) of E4HBA epoxy resins after tensile test with the feature identification (red lines). 

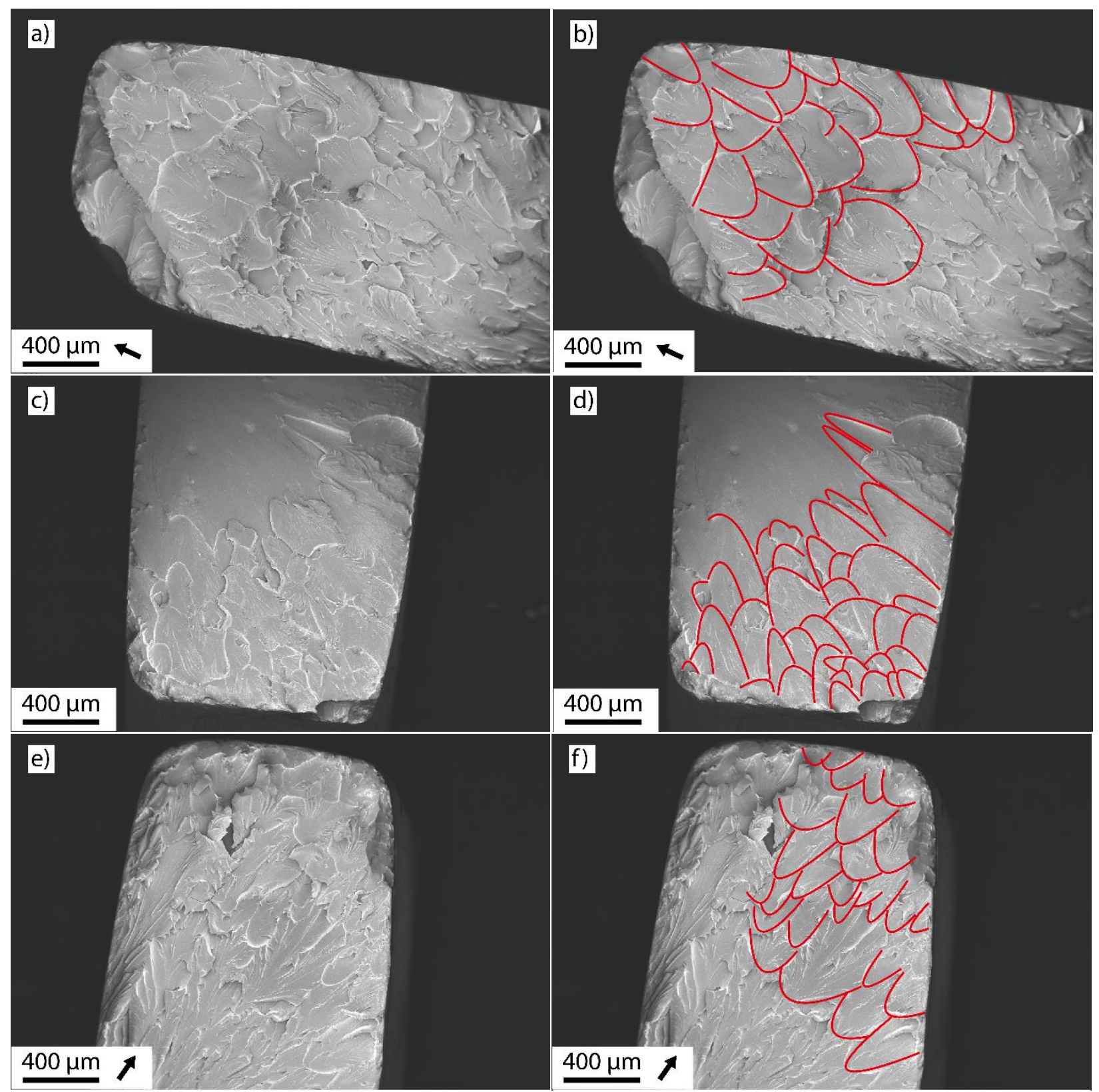

Figure S16: SEM micrographs of the fracture surface (grey level) of DGEBA epoxy resins after tensile test with the feature identification (red lines). 


\section{Reference}

1. Mohan, J., Organic Spectroscopy: Principles and Applications. CRC Press: Harrow, U.K., 2004. 